\title{
An out of body experience
}

\section{Reproductive and}

neonatal medicine have cut the minimum time that fetuses need to spend in the womb. Are completely artificial pregnancies in the offing? Jonathan Knight investigates.

0 cott Gelfand wants us to learn a lesson from cloning. When Dolly the sheep burst onto the public stage in 1997, ethicists and politicians were caught by surprise. Five years later, legislation around the world is still being updated. Gelfand, director of the Ethics Center at Oklahoma State University in Tulsa, is determined not to let the same thing happen with the artificial womb. So in February, he hosted a conference entitled: 'The end of natural motherhood? The artificial womb and designer babies.'

No one in attendance believed that Aldous Huxley's Brave New World, in which fetuses were nurtured in the laboratory rather than the womb, is about to become reality. But research into how to help premature babies has already allowed those born as young as 24 weeks into pregnancy to live. In vitro fertilization (IVF) now allows embryos

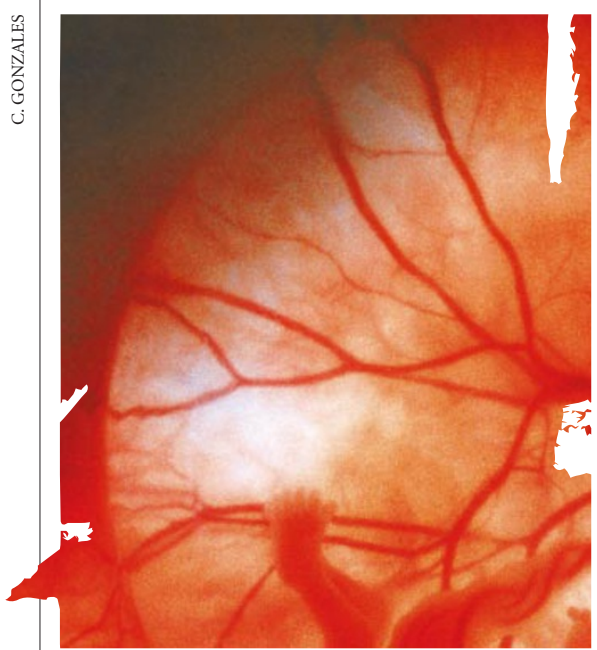

Brave new world? Scott Gelfand says we must debate the ethics of artificial wombs now.

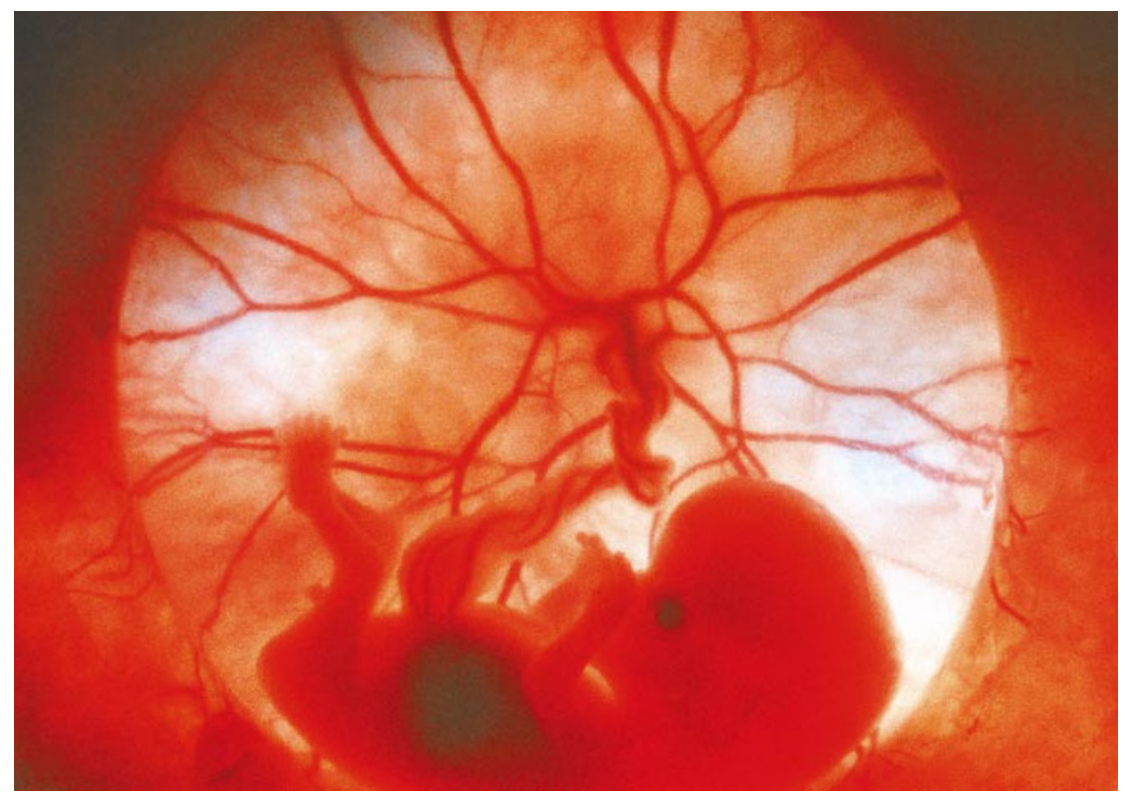

to be cultured for up to three days before being implanted, and researchers believe that longer times may be possible. If current methods were pushed to their absolute limit, normal human gestation could, in theory, be halved to 20 weeks, although not without probable harm to the fetus. "At some point the two ends will connect," Gelfand claims. "We need to start thinking about this now."

The researchers behind these projects say that they are not trying to turn pregnancy into a laboratory procedure and, in any case, the technology to nurture a fetus's normal development throughout gestation remains in the realms of science fiction. But even at its present stage, the research is posing some tough ethical questions that impinge on the contentious ground of abortion politics.

\section{Premature problems}

So far, most attention has focused on helping premature infants to survive. The lungs of babies born more than four weeks premature usually lack a foamy surfactant liquid that stops the organs from collapsing between breaths. This can often be overcome using surfactant chemicals, together with mechanical breathing aids, which can help infants born as young as 24 weeks to survive.

But very premature babies can still end up mentally impaired, and mechanical ventilation can damage the lungs. Thomas Shaffer, a neonatal physiologist at Temple University in Philadelphia, believes that liquid ventilation could help. In the womb, the fetus receives oxygen through the umbilical cord, and its lungs are filled with protective amniotic fluid. But at about 23 weeks, a fetus's lungs are ready to take in oxygen. So, in theory, premature babies could get oxygen from a fluid in their lungs. This should be a gentler alternative to forced ventilation and might deliver oxygen to the brain more efficiently than other methods, which in turn might reduce the chance of brain damage occurring.

Shaffer began testing liquid ventilation in the early 1980s. He filled the lungs of 18week-old lamb fetuses with a perfluorinated hydrocarbon that had been infused with oxygen. These inert organic compounds have a remarkable ability to carry oxygen, and are also being experimented with as substitutes for blood transfusions. Shaffer found that the fluid provided a better flow of oxygen to the blood than forced ventilation ${ }^{1}$.

Then, by accident, his supplier sent a ewe that was only 14 weeks pregnant, which Shaffer only discovered when he was removing the fetus. To his surprise, the animal's immature lungs responded just as well as those in the older lambs ${ }^{2}$, suggesting that the technique could be used in very premature infants.

In 1989, Shaffer attempted a short application of liquid ventilation on three human babies at St Christopher's Hospital for Children in Philadelphia, the most premature of which was just 23 weeks old. The infants, who had failed to respond to other treatments, survived for less than a day after the

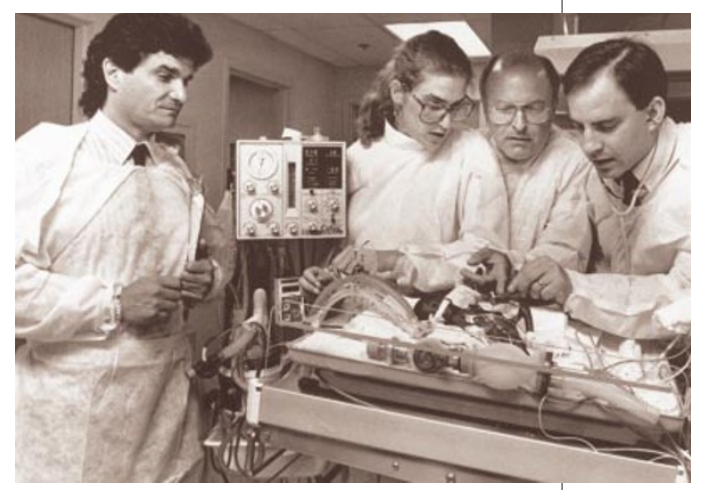

Thomas Shaffer (far left) and his team hope that fluids could help premature babies to breathe. 
fluid ventilation was removed, but two received more oxygen to the blood while they were given liquid instead of air, and all three had improved lung expansion ${ }^{3}$.

A 1996 clinical trial also provided positive results. Thirteen infants, born after 24-34 weeks with severe breathing difficulties, were given oxygenated liquid for between four hours and three days. Although none had been expected to survive, seven were discharged from hospital and appeared to be healthy and normal months later ${ }^{4}$. Those that Shaffer has followed up since are still doing fine. But he cannot find a drug company willing to continue with the clinical experiments. Shaffer suspects that the small size of the neonatal market deters firms from taking on the costs of the clinical trials.

\section{Direct line}

Other researchers have worked on systems that could help babies born even earlier by oxygenating the blood directly. Several groups pursued this approach in animal experiments in the 1960s and 1970s, before assisted ventilation became established. But Yoshinori Kuwabara, then at the University of Tokyo, continued in the hope that the method might treat very premature infants and could aid research into fetal physiology.

In 1990, his team used what was essentially an artificial placenta to keep mid- to latestage goat fetuses alive. Catheters carrying nutrient-enriched blood were threaded into the umbilical arteries and veins of the goat fetuses, which were held in a tank of artificial amniotic fluid. Early attempts were complicated because the fetuses tended to pinch or pull out the catheters as they twisted and kicked, so Kuwabara paralysed them with a muscle relaxant. This allowed two goats extracted from the womb three weeks early to survive until their normal term ${ }^{5}$. Unfortunately, the relaxant prevented the fetuses from developing muscle tone, and they could not stand or breathe unassisted. When the researchers removed the ventilator after four weeks, the goats died within hours.

The project moved to Juntendo University in Tokyo in 1992, and continued there after Kuwabawa's death in 2000 - although the researchers are now using the technique to study the flow of blood around the fetal brain. Plans to develop a treatment for premature babies are on hold until they work out how to solve the catheter problem. But Nobuya Unno, a member of Kuwabawa's team who is now at Nagano Children's Hospital, argues that this type of incubation could potentially be used to help babies born at about 20 weeks to survive until their lungs are mature enough to allow fluid ventilation to be used.

Establishing an artificial placenta for babies born earlier than that is likely to be difficult. Before 20 weeks, umbilical blood vessels are too narrow to accept catheters. The blood must also be infused with an anticoagulant to
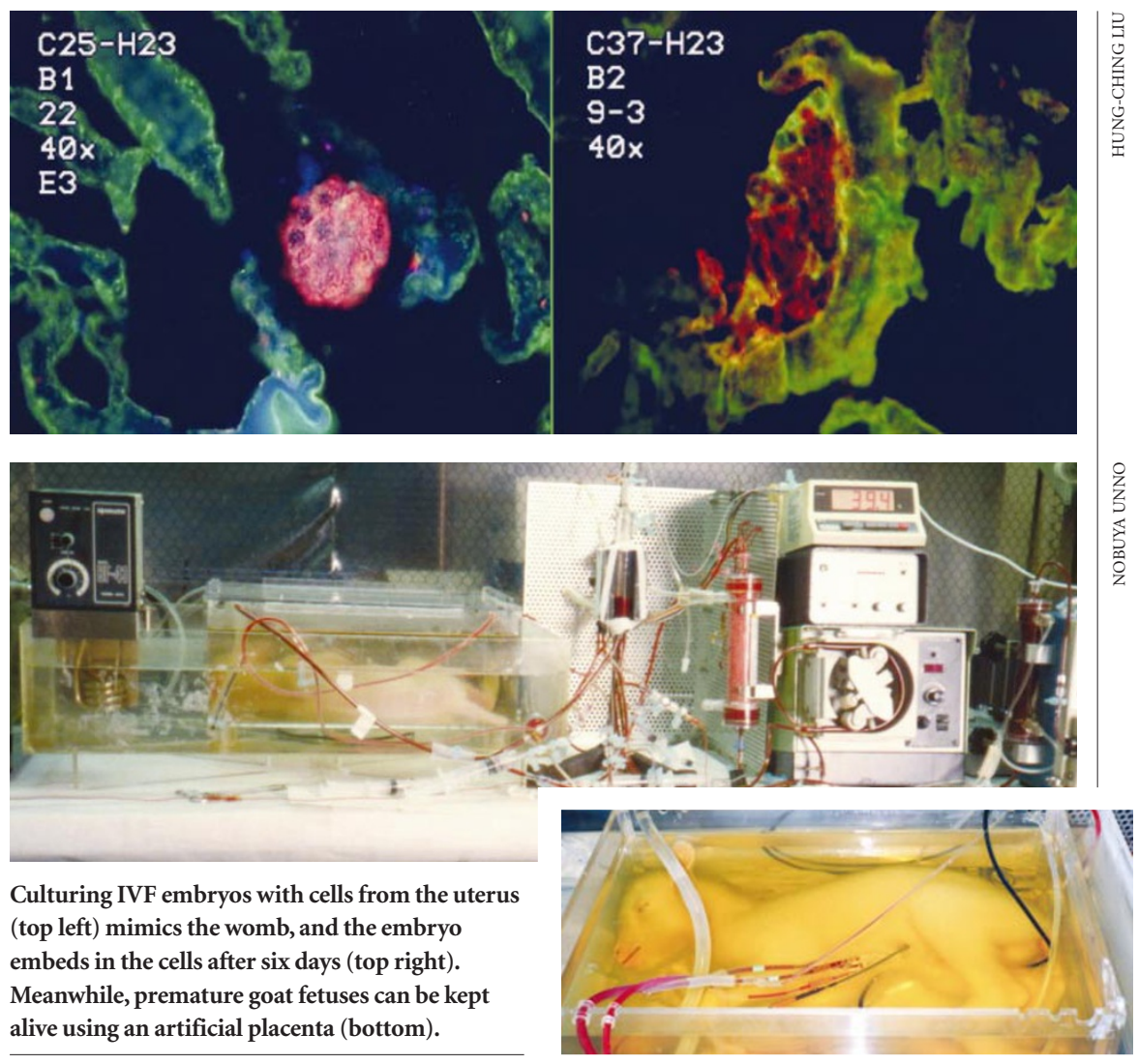

stop it clotting in the machinery, and anticoagulants tend to cause brain haemorrhaging in very immature fetuses. Although the barriers are not insurmountable, Unno says that he has no interest in pursuing such an approach.

\section{Fertile ground}

More recently, IVF research has been chipping away at the other end of gestation. Hung-Ching Liu, an embryologist at Cornell University's Center for Reproductive Medicine and Infertility in New York, is studying how the embryo attaches itself to the lining of the womb, known as the endometrium. She uses an IVF technique in which a fertilized human egg is cultured with endometrial cells before implantation, but she has modified the process so that the endometrial cells are first grown in a collagen matrix contained in a plastic well less than a centimetre wide. This causes the cells to form multilayered plugs similar to the tissue of the uterine lining.

In unpublished work, Liu found that the fertilized eggs attached themselves to the plugs of endometrial cells at six days postfertilization - just as they do in the womb. Liu hopes that growing embryos in such uterus-like conditions before implanting them will improve the success rate of IVF. She plans to extend her experiments to 14 days after fertilization to study how the placenta begins to grow, but says she has no interest in going beyond this stage.

As with the Japanese work, Liu's experi- ments have generated media claims that an artificial womb is on the horizon. All of the researchers dismiss this as speculation, but for Gelfand, it flags up the need to begin talking about the ethical issues. Delegates at his conference asked whether the technology could, for example, offer infertile couples who do not want to use a surrogate mother a chance of having their own baby. But under what circumstances should they be allowed to do so?

Attempts to boost the survival of premature babies are already raising difficult questions about time limits on abortions. In Britain, for example, a woman can under most circumstances legally have an abortion no later than 24 weeks into her pregnancy. This limit was reduced from 28 weeks in 1990, in part because medical advances meant that infants born at this stage could survive. Should further advances rescue even younger fetuses, the pressure to reduce the age again could mount.

Given the incendiary nature of the abortion debate, research at the frontiers of neonatal medicine seems certain to keep Gelfand and other ethicists busy - even if the spectre of Huxley's novel remains a distant prospect.

Jonathan Knight writes for Nature from San Francisco.

1. Shaffer, T. H., Douglas, P. R., Lowe, C. A. \& Bhutani, V. K.

Pediatr. Res. 17, 303-306 (1983).

2. Shaffer, T. H., Tran, N., Bhutani, V. K. \& Sivieri, E. M. Pediatr. Res. 17, 680-684 (1983).

3. Greenspan, J. S., Wolfson, M. R., Rubenstein, S. D. \& Shaffer, T. H. J. Pediatr. 117, 106-111 (1990).

4. Leach, C. L. et al. N. Engl. J. Med. 335, 761-767 (1996)

5. Unno, N. et al. Artif. Organs 17, 996-1003 (1993). 